Canadian Journal of Plant Science Revue canadienne de phytotechnie

\title{
Gender effects on Salix suchowensis growth and wood properties as revealed by a full-sib pedigree
}

\begin{tabular}{|r|l|}
\hline Journal: & Canadian Journal of Plant Science \\
\hline Manuscript ID & CJPS-2016-0153.R1 \\
\hline Danuscript Type: & Article \\
\hline Complete List of Authors: & $\begin{array}{l}\text { Hou, Jing; Nanjing Forestry University } \\
\text { Guo, Zengchao; Qilu Medical University } \\
\text { Liu, Hailin; Nanjing Forestry University } \\
\text { Yin, Tongming; Nanjing Forestry University, }\end{array}$ \\
\hline Keywords: & Biochemistry, Biomass \\
\hline \multicolumn{2}{|l}{} \\
\hline
\end{tabular}




\title{
Gender effects on Salix suchowensis growth and wood properties as revealed by a full-sib pedigree
}

\author{
Jing Hou ${ }^{1 \S}$, Zengchao Guo ${ }^{2 \S}$, Hailin Liu ${ }^{1}$, and Tongming Yin ${ }^{1}$

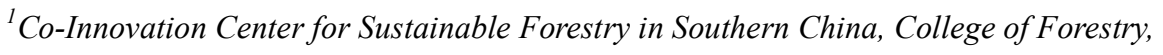 \\ Nanjing Forestry University, Nanjing 210037, China and ${ }^{2}$ Qilu Medical University, Zibo \\ 255213, China.
}

${ }^{\S}$ These authors contributed equally to this work
Corresponding author: Tongming Yin
Co-Innovation Center for Sustainable Forestry in Southern China, College of Forestry,
Nanjing Forestry University, 159 Longpan Road, Nanjing, 210037, China.
Email: tmyin@njfu.com.cn;
Phone: 01186-25-85428165;
Fax: 01186-25-85427165. 
Abstract: Among dioecious plant species, it is common for the males to grow faster than the females. In this study, we investigated the effects of gender on the growth and wood properties of Salix suchowensis using a full-sib pedigree. We observed that the segregation of sex followed a 1:1 ratio, and that gender significantly affected growth traits, including tree height, ground diameter, and biomass production. Additionally, the females generally performed better than the males, which is contrast to the common scenario for dioecious plant species. There is currently relatively little information regarding the gender effects on wood properties. Therefore, we also measured the basic wood density and cellulose, hemicellulose, and lignin contents. We determined that any differences between the male and female trees regarding these wood property traits were insignificant. Recent studies revealed that the sex of willow trees is controlled by a ZW sex determination system in which the female is theheterogenic gender. Because female heterogamety is relatively rare in higher plants, our findings may be relevant for characterizing the gender effects on biological performance in dioecious plants regulated by the ZW sex determination system. Key words: Salix suchowensis, gender, growth, wood property, ZW sex determination system. 


\section{Introduction}

Dioecy in plants has attracted considerable attention among botanists since Darwin's time (Wang and Griffin 2003). Dioecy refers to the division of male and female reproductive functions in separate individuals, in which males produce pollen and females produce seeds (Lloyd and Webb 1977). Although dioecious species represent only about $4-6 \%$ of the total number of higher plant species (Renner and Ricklefs 1995), they are important components of terrestrial ecosystems. Sex-related differences in the vegetative growth of sexually dimorphic plants have long been a primary research interest (Lloyd and webb 1977; Sakai and Sharik 1988). Seed production was reported to require more resources than pollen production. Consequently, the greater allocation of resources toward vegetative growth in male plants led researchers to assume that males exhibit superior growth traits (Lloyd and Webb 1977; Elmqvist et al. 1991). Previous studies concluded that the male plants of several dioecious species perform better in terms of vigor and form than the female plants (Farmer 1964; Allen and Antos 1993; Shea et al. 1993). However, other studies revealed that females are commonly capable of growing as quickly as males (Gauquelin et al. 2002) or sometimes even faster (Grant and Mitton 1979; Gross and Soule 1981).

Growth performance affects the competitiveness of a particular individual. Willows (Salix species) and poplars (Populus species) are dioecious plants in the family Salicaceae. Early empirical observations in natural populations of several Populus species revealed a 
preponderance of males and male superiority in vigor and form, especially under harsh environmental conditions (Farmer 1964). In contrast, most studies detected female-biased sex ratios in natural willow populations, likely due to various environmental and ecological factors (Crawford and Balfour 1983; Elmqvist et al. 1988; Crawford and Balfour 1990; Danell et al. 1991). A 1:1 male to female ratio has occasionally been observed in natural willow populations (Kaul and Kaul 1984). Alström-Rapaport et al. (1997) reported that under homogeneous environmental conditions, the sex ratio ranged from an extreme female bias to an extreme male bias in 13 full-sib families of $S$. viminalis. Their study suggested that $S$. viminalis gender determination followed a multilocus epistatic model. However, more recent studies have consistently shown that the sex of willow species, including $S$. viminalis, is governed by a single locus (Semerikov et al. 2003; Hou et al. 2015; Pucholt et al. 2015). The sex of willows is determined by the ZW system in which the female is the heterogametic gender (Hou et al. 2015; Pucholt et al. 2015). In most of the aforementioned studies, only a limited number of individuals were investigated. For a more comprehensive characterization of gender segregation and the effects of gender on growth, experiments involving a large number of individuals with homogeneous genetic and environmental backgrounds are necessary.

In addition to its effect on growth, gender may also affect wood quality. Wood is composed of the following three major chemical components: cellulose, hemicellulose, and lignin. Cellulose and hemicellulose are polysaccharides that form a considerable part of the 
dry mass of wood (Chow and Rolfe 1989). Lignin is a type of phenolic polymer that consists of three hydroxycinnamyl alcohol precursors (Boerjan and Baucher 2003; Davin and Lewis 2005). Wood compositions affect cell wall structures and functions, and ultimately influence the commercial value of the raw material (Plomion et al. 2001; Boudet et al. 2003; Yin et al. 2010). The cellulose, hemicellulose, and lignin biosynthetic pathways are affected by hormones produced by males and females during the growth process. Thus, the contents of these major chemical components may vary between males and females. Because of a lack of experimental data, the gender effects regulating the wood properties of dioecious woody plants have not been fully characterized.

Salix suchowensis is a shrub willow that is widely distributed in central China. This willow species is mainly used as a source of basket-weaving material, and its application was first recorded in a document from the Autumn-Spring Period in China (B.C. 300). Because of its excellent coppicing ability, S. suchowensis is also considered to be a promising woody species for biomass plantations. Seedlings of this perennial shrub willow can be $2 \mathrm{~m}$ tall, and they can reach sexual maturity 1 year after being transplanted in the field. Unlike the gigantic trees, S. suchowensis is an early-flowering plant that is easily hybridized with other species. Additionally, because it is small, it is a desirable plant material for investigating the gender effects on the biological performance of dioecious plants. In this study, we produced a large full-sib pedigree for this willow species, and conducted a large-scale field trial with many progenies in their natural habitat. In dioecious 
plant species, the males are commonly the heterogamic gender (Ming et al. 2011), and normally exhibit superior vigor and form when compared with the females. In contrast, the females are the heterogamic gender in willows (Hou et al. 2015; Pucholt et al. 2015). The objectives of this study were as follows: (1) study the sex segregation ratio of this willow species under a homogeneous environmental background and (2) investigate the gender effects on plant growth and wood properties. Because plant species with heterogamic females are relatively uncommon (Charlesworth 2013), this study may provide unique insights into the gender effects of dioecious plants that are regulated by the ZW sex determination system.

\section{Materials and Methods}

\section{Materials}

A full-sib cross was established in February 2010. The maternal parent was sampled from Xinyi, Jiangsu, China, while the paternal parent was collected from Linshu, Shandong, China. At the end of March, mature seeds were collected and immediately sown in a seedbed maintained in a greenhouse. Two months later, seedlings were transferred to individual containers and grown in the greenhouse untill the end of October. The cultivated seedlings were planted in a field nursery $(30 \mathrm{~cm} \times 30 \mathrm{~cm})$ in a random order. A border consisting of two rows of cuttings from the maternal parent surrounded all sides of the field. The field trial was conducted at the Chenwei Forest Farm in Sihong County, Jiangsu, China, which is located at the center of the natural habitat of S. suchowensis. 


\section{Gender assessment}

All progenies reached sexual maturity 1 year after seedlings were transferred to the field.

Willow flowers bloom in early spring before the leaves appear, and the male and female flowers are arranged in morphologically different catkins. The flowers are attached to the rachis of the catkin and are seated in a cup-shaped disk. The male and female willow flowers lack calyx or corolla. The male flowers consist of a group of stamens inserted on a disk, while the female flowers include a single-celled ovary seated in a cup-shaped disk (Fig. 1). In February 2012, the gender of each individual was determined based on the distinct features of male and female flowers.

\section{Growth trait measurements}

At the end of December 2013, the aerial parts of each seedling growing in the field were harvested. We measured the growth traits, including tree height, ground diameter, and fresh biomass. Tree height was determined using a measuring tape at a precision of $0.1 \mathrm{~cm}$, and the ground diameter was measured with a vernier caliper at a precision of $0.01 \mathrm{~mm}$. The biomass of the aerial plant parts was determined using an analytical balance at a precision of $0.01 \mathrm{~g}$.

\section{Wood basic density measurement}

Wood basic density was measured according to a water displacement method (Olesen 1971). The bark was removed from the stems of a randomly selected subset of 130 progenies (i.e., 65 males and 65 females). A 5-cm sample was collected from the lower part 
of the stem of each individual, and used for wood basic density measurements. The rest of the stem sample was oven-dried at $105{ }^{\circ} \mathrm{C}$ and then ground to a powder. The powdered samples were filtered through an 18-mesh sieve and stored in sealed plastic bags for subsequent analyses of chemical compositions. The wood basic density was calculated according to the following formula: $\rho_{\mathrm{y}}=\mathrm{m}_{0} / \mathrm{V}_{\max }$, where $\rho_{\mathrm{y}}$ represents the wood basic density $\left(\mathrm{g} \mathrm{cm}^{-3}\right), \mathrm{m}_{0}$ refers to the oven-dried mass $(\mathrm{g})$, and $\mathrm{V}_{\max }$ represents the saturated volume $\left(\mathrm{cm}^{3}\right)$. The oven-dried mass was obtained by drying the samples at $105{ }^{\circ} \mathrm{C}$ until they reached a constant weight. The oven-dried samples were soaked in water, and the saturated volume was calculated according to drainage method (Olesen 1971).

\section{Major chemical composition measurements}

The hemicellulose, cellulose, and lignin contents of the aforementioned 130 progenies were measured according to the detergent fiber analysis method described by Van Soest et al. (1991). The neutral detergent fiber (NDF), acid detergent fiber (ADF), acid detergent lignin (ADL), and acid insoluble ash (AIA) contents were measured using the FIWE 6 raw fiber determination system (Velp Scientifica, Italy). For the NDF measurement, a mixture containing $1 \mathrm{~g}$ wood sample, $0.5 \mathrm{~g}$ sodium sulfite, $100 \mathrm{ml}$ neutral detergent, and 3-5 drops n-caprylic alcohol was heated to reflux for $1 \mathrm{~h}$. The mixture was filtered and the solid material was washed with boiling water and acetone. The remaining precipitated material was oven-dried at $105^{\circ} \mathrm{C}$ until reaching a constant weight, after which the NDF content was measured. To measure the ADF content, a mixture containing the residue from the 
NDF analysis, $100 \mathrm{ml}$ acid detergent and 3-5 drops n-caprylic alcohol was heated to reflux for $1 \mathrm{~h}$. The mixture was treated as described above prior to measuring the ADF content. To analyze the ADL content, $30 \mathrm{ml}$ sulfuric acid (72\%) was added to the residue remaining following the $\mathrm{ADF}$ measurement. The mixture was incubated at room temperature for $3 \mathrm{~h}$. The remaining precipitated material was washed with boiling water and oven-dried to a constant weight at $105{ }^{\circ} \mathrm{C}$, after which the $\mathrm{ADL}$ content was measured. Finally, the remaining residue was incubated in a muffle furnace at $550{ }^{\circ} \mathrm{C}$. To determine the AIA content, the resulting ash was cooled in a desiccator and weighed.

\section{Statistical analysis}

Data were analyzed using the SPSS package (Coakes and Steed 2001).

\section{Results}

\section{Segregation of gender}

Based on floral features, 273 and 285 progenies were identified as males and females, respectively. A Chi-square test revealed that the sex ratio of the progenies did not significantly depart from a 1:1 segregation ratio $\left(\chi^{2}=0.2581,<\chi_{0.05}^{2}=3.841\right)$.

\section{Gender effects on growth traits}

Growth traits, including tree height, ground diameter, and fresh biomass, were measured for 558 progenies of the established S. suchowensis pedigree (Table 1). An analysis of the ground diameter, tree height, and biomass data revealed that the largest ground diameter $(15.88 \mathrm{~mm})$ was observed for a female sample. The tallest tree $(298.5 \mathrm{~cm})$ was also female. 
The shortest tree $(95.5 \mathrm{~cm})$ and the tree with the lowest biomass $(12.29 \mathrm{~g})$ were males. However, the highest biomass $(513.60 \mathrm{~g})$ was observed in a male individual. The mean values of these parameters were all greater in the female trees. The analysis of variance revealed significant differences between the male and female individuals $(p<0.01)$ (Table 2). Therefore, the females performed significantly better than the males in terms of growth traits.

\section{Variations in wood basic density and chemical compositions between genders}

Basic density is one of the most important properties of wood, and considerably affects the quality and economic value of wood products. Wood density varies with growth conditions and measured samples. Generally, the stems are denser than the branches. Additionally, faster growth is usually associated with lower wood density (Gapare et al. 2010). For comparisons, we sampled the same part of each plant (Table 3). The lowest wood basic density value was recorded for a male individual, while the highest value was observed for a female tree. The average wood basic density of female trees was higher than that of male trees. However, the analysis of variance indicated that the difference in wood basic density between male and female trees was insignificant.

In addition to wood basic density, the main chemical components of wood are also very important parameters affecting wood quality. In this study, we analyzed the cellulose, hemicellulose, and lignin contents. The lowest cellulose (47.91\%), hemicellulose (16.52\%), and lignin $(12.28 \%)$ contents were detected in male samples. In contrast, the highest 
cellulose $(57.00 \%)$, hemicellulose $(23.76 \%)$, and lignin $(16.43 \%)$ contents were detected in female trees. Although there were slight differences between the male and female trees, the analysis of variance indicated these differences were not significant (Table 4).

\section{Discussion}

A female-biased sex ratio is commonly observed in natural populations of willow species (Crawford and Balfour 1983; Elmqvist et al. 1988; Crawford and Balfour 1990; Danell et al. 1991). This bias is partly due to differential feeding by mammalian herbivores (Elmqvist et al. 1988; Danell et al. 1991) and a lower viability of males (Crawford and Balfour 1990; Åhman 1997). In this study, analyses of growth traits indicated that gender significantly affected on growth, with females generally performing better than males. In natural willow populations, plants normally occur in cohorts, and fast-growing individuals will be more competitive, which increases their survival rate. Coppice willows are appropriate for vegetative propagation. Female willows tend to undergo vegetative propagation more extensively propagated than male plants because of their superior growth traits. Thus, the reproductive habit of willows is likely an important factor influencing the sex ratio bias. Several studies have concluded that male and female willows respond differently to environmental factors, with females normally performing better than males under stress conditions (Crawford and Balfour 1983; Elmqvist et al. 1988; Crawford and Balfour 1990; Danell et al. 1991). We conducted this study in the central area of the natural $S$. suchowenesis habitat, and determined that gender segregated in a 1:1 ratio. Under favorable 
environmental conditions, there is unlikely to be any selective pressure favoring the male or female plants. It is noteworthy that the gender segregation ratio in the analyzed pedigree indicated that the gender of willows was governed by a single locus, which is consistent with the findings of earlier studies (Semerikov et al. 2003; Hou et al. 2015; Pucholt et al. 2015). It is unlikely that the gender of willows is regulated by multiple loci as indicated by Alström-Rapaport et al. (1997)

Recent studies revealed that unlike the XY sex determination system (i.e., male heterogamety) in many higher plants, willows are regulated by a ZW sex determination system (i.e., female heterogamety) (Hou et al. 2015; Pucholt et al. 2015). Plant species with heterogamic females are relatively uncommon (Charlesworth 2013). Therefore, willow trees provide a unique system for exploring the gender effects in such plants. In this study, we analyzed a full-sib pedigree. Because gender was the only factor under consideration, all other genetic differences were homogenized between the males and females in the analysis of variance. Compared with natural populations, a full-sib pedigree may be more appropriate for eliminating the effects of factors other than the gender locus itself. Additionally, we grew plants under relatively uniform field conditions to eliminate environmental effects. Thus, our experimental design enabled us to focus on gender effects. Based on a sample of 273 males and 285 females, we revealed that gender significantly affected growth traits, with the females generally growing faster than the males. These findings were consistent with the results of a previous study involving S. arctica (Crawford 
and Balfour 1990). It is noteworthy that these observations were inconsistent with the hypothesis that female willow trees consume more resources for sexual reproduction than male willow trees, thereby leading to slower vegetative growth. Elmqvist et al. (1991) reported that female willows have relatively high concentrations of tannin and salicortin, which provide protection from vertebrate herbivores. This finding was confirmed in another study in which male willows were damaged more than female willows by herbivores feeding on vegetative tissues (Hjältén 1992). However, the plant materials in our study were not exposed to similar stresses. Whether the female growth superiority is associated with the ZW sex determination system is an interesting question worthy of further study.

Previous investigations focused on the morphological and physiological differences between the male and female plants of many dioecious species (Dawson and Bliss 1989; Laporte and Delph 1996; Espirito-Santo et al. 2003). However, little is known about the gender effects on wood properties. To the best of our knowledge, our study is the first to study this aspect. We observed that although there were significant growth differences between the female and male willow trees, gender did not significantly affect basic wood density and cellulose, hemicellulose, and lignin contents.

S. suchowensis is a small shrub that reaches sexual maturity relatively early. All plants flowered within 1 year of being transplanted from containers in the greenhouse to the field. During the commercial production of S. suchowensis, trees are normally annually harvested before flowering. For tree species with a long juvenile period, growth traits and wood 
properties are normally investigated at age of the half rotation cycle. In this study, shrub willow progenies were grown in a container for 1 year and in the field for 2 years. These plant materials should be appropriate for investigating the gender effects in this early-flowering willow species. This study provides essential information for characterizing the gender effects on the growth and wood properties of willows.

\section{Author contribution statement}

HJ, GZC, and LHL perform the lab work and data analysis. HJ, GZC, and YTM wrote the paper, YTM conceived and designed the experiments

\section{Acknowledgments}

This work was supported by the Key Forestry Public Welfare Project (201304102), and the Natural Science Foundation of China (31561123001, 31570662). It was also enabled by the Innovative Research Team of the Educational Department of China, the Doctorate Fellowship Foundation and PAPD (Priority Academic Program Development) program at Nanjing Forestry University, and graduate student scientific research innovation project in ordinary university of Jiangsu province (KYLX15_0905).

\section{Conflict of interest}

The authors declare that they have no conflict of interest.

\section{References}

Åhman, I. 1997. Growth, herbivory and disease in relation to gender in Salix viminalis L.

Oecologia. 111: 61-68. 
Allen, G.A., and Antos, J.A. 1993. Sex ratio variation in the dioecious shrub Oemleria cerasiformis. Am. Nat. 141: 537-553.

Alström-Rapaport, C., Lascoux, M., and Gullberg, U. 1997. Sex determination and sex ratio in the dioecious shrub Salix viminalis L. Theor. Appl. Genet. 94: 493-497.

Boerjan, W.J., and Baucher, R.M. 2003. Lignin biosynthesis. Ann. Rev. Plant Biol. 54: 519-546.

Boudet, A.M., Kajita, S., Grima-Pettenati, J., and Goffner, D. 2003. Lignins and lignocellulosics: a better control of synthesis for new and improved uses. Trends Plant Sci. 8: 576-581.

Chow, P., and Rolfe, G.L. 1989. Carbon and hydrogen contents of short-rotation biomass of five hardwood species. Wood Fiber Sci. 21: 30-36.

Coakes, S.J., and Steed, L.G. 2001. SPSS Analysis Without Anguish. Wiley, New York.

Charlesworth, D. 2013. Plant sex chromosome evolution. J. Exp. Bot. 64: 405-420.

Crawford, R.M.M., and Balfour, J. 1983. Female predominant sex ratios and physiological differentiation in arctic willows. J. Ecol. 71: 149-160.

Crawford, R.M.M., and Balfour, J. 1990. Female-biased sex ratios and differential growth in arctic willows. Flora. 184: 291-302.

Danell, K., Hjältén, J., Ericson, L., and Elmqvist, T. 1991. Vole feeding on male and female willow shoots along a gradient of plant productivity. Oikos. 62: 145-152.

Davin, L.B., and Lewis, N.G. 2005. Lignin primary structures and dirigentsites. Curr. Opin. 
Biotech. 16: 407-415.

Dawson, T.E., and Bliss, L.C. 1989. Patterns of water use and the tissue water relations in the dioecious shrub Salix arctica: the physiological basis for habitat partitioning between the sexes. Oecologia. 79: 332-343.

Elmqvist, T., Cates, R.G., Harper, J.K., and Gardfjell, H. 1991. Flowering in males and females of a Utah willow, Salix rigida and effects on growth, tannins, phenolic glycosides and sugars. Oikos. 61: 65-72.

Elmqvist, T., Ericson, L., Danell, K., and Salomonson, A. 1988. Latitudinal sex ratio variation in willows, Salix spp., and gradients in vole herbivory. Oikos. 51: 259-266.

Espirito-Santo, M.M., Madeira, B.G., Neves, F.S., Faria, M.L., Fagundes, M., and Fernandes, G.W. 2003. Sexual differences in reproductive phenology and their consequences for the demography of Baccharis dracunculifolia (Asteraceae), a dioecious tropical shrub. Ann. Bot. 91:13-19.

Farmer, R.E. 1964. Sex ratio and sex-related characteristics in eastern cottonwood. Silvae Genet. 13: 116-118.

Gapare, W.J., Ivković, M., Baltunis, B.S., Matheson, C.A., and Wu, H.X. 2010. Genetic stability of wood density and diameter in Pinus radiata D. Don plantation estate across Australia. Tree Genet. Genomes. 6: 113-125.

Gauquelin, T., Bertaudière-Montès, A., Badri, W., and Montès, N. 2002. Sex ratio and sexual dimorphism in mountain dioecious thuriferous juniper (Juniperus thurifera L., 
Cupressaceae). Bot. J. Linn. Soc. 138: 237-244.

Grant, M.C., and Mitton, J.B. 1979. Elevational gradients in adult sex ratios and sexual differentiation in vegetative growth rates of Populus tremuloides Michx. Evolution. 33: 914-918.

Gross, K.L., and Soule, J.D. 1981. Differences in biomass allocation to reproductive and vegetative structures of male and female plants of a dioecious, perennial herb, Silenealba (Miller) Krause. Am. J. Bot. 68: 801-807.

Hjältén, J. 1992. Plant sex and hare feeding preferences. Oecologia. 89: 253-256.

Hou, J., Ye, N., Zhang, D., Chen, Y., Fang, L., Dai, X., and Yin, T. 2015. Different autosomes evolved into sex chromosomes in the sister genera of Salix and Populus. Sci. Rep-UK. 5: 9076.

Kaul, R.B., and Kaul, M.N. 1984. Sex ratios of Populus deltoides and Salix amygdaloides (Salicaeae) in Nebraska. Southwest. Nat. 29: 265-269.

Laporte, M.M., Delph, L.F. 1996. Sex-specific physiology and source-sink relations in the dioecious plant Silene latifolia. Oecologia. 106: 63-72.

Lloyd, D.G., and Webb, C.J. 1977. Secondary sex characters in plants. Bot. Rev. 43: $177-216$.

Ming, R., Bendahmane, A., and Renner, S.S. 2011. Sex chromosomes in land plants. Annu. Rev. Plant Biol. 62:485-514.

Olesen, P.O. 1971. Water displacement method. A fast and accurate method to determine 
green volume of wood samples. For. Tree Improv. 3: 3-23.

Plomion, C., Leprovost, G., and Stokes, A. 2001. Wood formation in trees. Plant physiol. 127: $1513-1523$.

Pucholt, P., Rönnberg-Wästljung, A.C., and Berlin, S. 2015. Single locus sex determination and female heterogamety in the basket willow (Salix viminalis L.). Heredity. 114: 575-583.

Renner, S.S., and Ricklefs, R.E. 1995. Dioecy and its correlates in the flowering plants. Am. J. Bot. 82: 596-606.

Sakai, A.K., and Sharik, T.L. 1988. Clonal growth of male and female bigtooth aspen (Populus grandidentata). Ecology. 69: 2031-2033.

Semerikov, V., Lagercrantz, U., Tsarouhas, V., Rönnberg-Wästljung, A., Alström-Rapaport, C., and Lascoux, M. 2003. Genetic mapping of sex-linked markers in Salix viminalis L. Heredity. 91: 293-299.

Shea, M.M., Dixon, P.M., and Sharitz, R.R. 1993. Size differences, sex ratio, and spatial distribution of male and female water tupelo, Nyssa aquatica (Nyssaceae). Am. J. Bot. 80: 26-30.

Van Soest, P.J., Robertson, J.B., and Lewis, B.A. 1991. Methods for dietary fibre, neutral detergent fibre, and non-starch polysaccharides in relation to animal nutrition. J. Dairy Sci. 74: 3583-3597.

Wang, X., and Griffin, K.L. 2003. Sex-specific physiological and growth responses to 
elevated atmospheric $\mathrm{CO}_{2}$ in Silene latifolia Poiret. Global Change Biol. 9: 612-618.

Yin, T., Zhang, X., Gunter, L., Priya, R., Sykes, R., Davis, M., Wullschleger, S.D., and Tuskan, G.A. 2010. Differential detection of genetic loci underlying stem and root lignin content in Populus. PLoS One. 5: e14021.

\section{Legends to figures}

Fig. 1 Female and male willow flowers 
Table 1. Ground diameter, tree height, and biomass of male and female willows

\begin{tabular}{clcccc}
\hline Growth traits & Sex & Number of trees & Mean \pm S.E & Range & CV (\%) \\
\hline $\begin{array}{c}\text { Group diameter } \\
(\mathrm{mm})\end{array}$ & Female & 285 & $10.66 \pm 1.88$ & $5.05-15.88$ & 17.64 \\
& Male & 273 & $10.09 \pm 1.72$ & $5.40-15.47$ & 17.05 \\
$\begin{array}{c}\text { Height } \\
(\mathrm{cm})\end{array}$ & Female & 285 & $216.4 \pm 30.8$ & $106.5-298.5$ & 14.23 \\
& Male & 273 & $209.1 \pm 30.6$ & $95.5-292.5$ & 14.63 \\
$\begin{array}{c}\text { Biomass } \\
(\mathrm{g})\end{array}$ & Female & 285 & $125.29 \pm 66.11$ & $16.71-402.59$ & 52.77 \\
\hline
\end{tabular}




\begin{tabular}{lccccccc}
\hline \multicolumn{1}{l}{$\begin{array}{l}\text { Table 2. Analysis of variance between male and female willows regarding ground } \\
\text { diameter, tree height, and biomass }\end{array}$} \\
\begin{tabular}{llllllll}
\hline Growth trait & $\begin{array}{r}\text { Source of } \\
\text { variation }\end{array}$ & SS & DF & MS & F & Sig. \\
\hline Ground diameter & Gender & 45.131 & 1 & 45.131 & 13.881 & $0.000^{* *}$ \\
tree height & Gender & 7570.934 & 1 & 7570.934 & 8.019 & $0.005^{* *}$ \\
Biomass & Gender & 27555.242 & 1 & 27555.242 & 6.977 & $0.008^{* *}$ \\
\hline
\end{tabular}
\end{tabular}

$a * *$ Significance $(\mathrm{p}<0.01)$ 
Table 3. Basic wood density and major chemical compositions of male and female willows

\begin{tabular}{clcccc}
\hline Wood property & Sex & $\begin{array}{c}\text { Number } \\
\text { of trees }\end{array}$ & Mean \pm S.E & $\begin{array}{c}\text { Rang } \\
(\text { min-max })\end{array}$ & $\begin{array}{c}\text { CV } \\
(\%)\end{array}$ \\
\hline Cellulose & male & 65 & $53.04 \pm 0.25$ & $47.91-56.59$ & 3.85 \\
$(\%)$ & female & 65 & $53.33 \pm 0.23$ & $49.03-57.00$ & 3.41 \\
Hemicellulose & male & 65 & $19.95 \pm 0.20$ & $16.52-23.10$ & 8.02 \\
$(\%)$ & female & 65 & $19.66 \pm 0.19$ & $16.94-23.76$ & 7.62 \\
Lignin & male & 65 & $14.05 \pm 0.11$ & $12.28-16.22$ & 6.12 \\
$(\%)$ & female & 65 & $14.33 \pm 0.10$ & $12.85-16.43$ & 5.79 \\
Basic density & male & 65 & $0.3862 \pm 0.0056$ & $0.2416-0.4968$ & 12.95 \\
$\left(\mathrm{~g} \mathrm{~cm}^{-3}\right)$ & female & 65 & $0.3991 \pm 0.0044$ & $0.3263-0.5044$ & 8.84 \\
\hline
\end{tabular}




\begin{tabular}{|c|c|c|c|c|c|c|}
\hline Wood property & $\begin{array}{l}\text { Source of } \\
\text { variation }\end{array}$ & SS & $\mathrm{DF}$ & MS & $\mathrm{F}$ & Sig. \\
\hline Cellulose content & Gender & 0.0003 & 1 & 0.0003 & 0.711 & 0.401 \\
\hline Hemicellulose content & Gender & 0.0003 & 1 & 0.0003 & 1.127 & 0.290 \\
\hline Lignin content & Gender & 0.0003 & 1 & 0.0003 & 3.472 & 0.065 \\
\hline Basic density & Gender & 0.0054 & 1 & 0.0054 & 3.243 & 0.074 \\
\hline
\end{tabular}




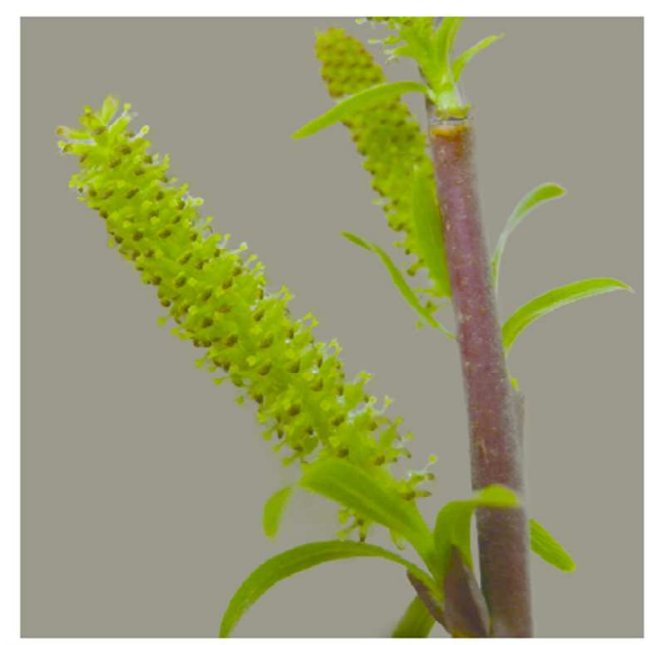

Female

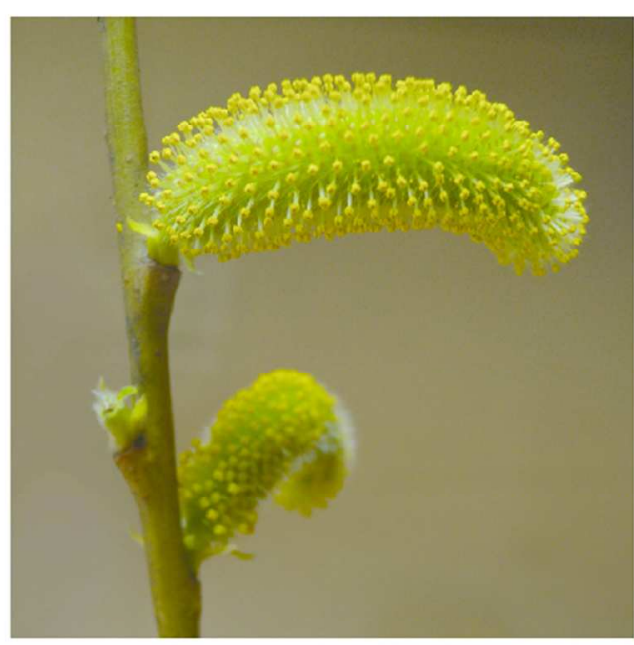

Male

Fig. 1 Female and male willow flowers

$76 \times 43 \mathrm{~mm}(300 \times 300$ DPI $)$ 